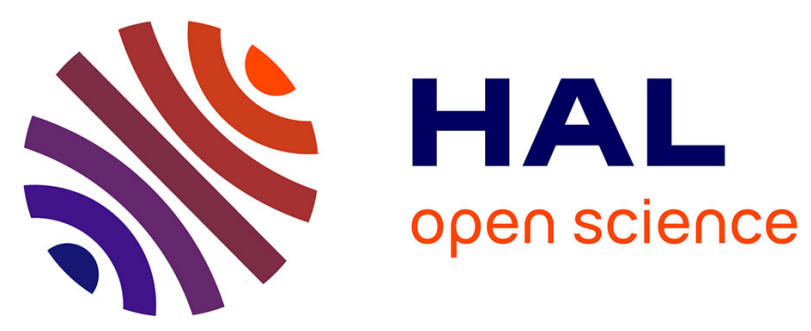

\title{
The mental health of doctor-shoppers: experience from a patient-led fee-for-service primary care setting.
}

\author{
Joanna L. Norton, Guilhem de Roquefeuil, Michel David, Jean-Philippe \\ Boulenger, Karen A. Ritchie, Anthony H. Mann
}

\section{To cite this version:}

Joanna L. Norton, Guilhem de Roquefeuil, Michel David, Jean-Philippe Boulenger, Karen A. Ritchie, et al.. The mental health of doctor-shoppers: experience from a patient-led fee-for-service primary care setting.. Journal of Affective Disorders, 2011, 131 (1-3), pp.428-32. 10.1016/j.jad.2010.12.009 . inserm-00618015

\section{HAL Id: inserm-00618015 https://www.hal.inserm.fr/inserm-00618015}

Submitted on 31 Aug 2011

HAL is a multi-disciplinary open access archive for the deposit and dissemination of scientific research documents, whether they are published or not. The documents may come from teaching and research institutions in France or abroad, or from public or private research centers.
L'archive ouverte pluridisciplinaire HAL, est destinée au dépôt et à la diffusion de documents scientifiques de niveau recherche, publiés ou non, émanant des établissements d'enseignement et de recherche français ou étrangers, des laboratoires publics ou privés. 
The mental health of doctor-shoppers: experience from a patient-led fee-for-service primary care setting.

Joanna Norton $^{\mathrm{a} *}$, Guilhem de Roquefeuil ${ }^{\mathrm{a}}$, Michel David ${ }^{\mathrm{b}}$, Jean-Philippe Boulenger ${ }^{\mathrm{a}, \mathrm{c}}$, Karen Ritchie $^{\mathrm{a}, \mathrm{d}}$, Anthony Mann ${ }^{\mathrm{a}, \mathrm{e}}$

${ }^{\text {a }}$ Inserm U888, Pathologies of the Nervous System, Montpellier, France

${ }^{\mathrm{b}}$ Department of General Practice, Montpellier University Medical Faculty, France

${ }^{\mathrm{c}}$ Department of Adult Psychiatry, La Colombière Hospital, Montpellier, France

${ }^{\mathrm{d}}$ Faculty of Medicine, Imperial College, Saint Mary’s Hospital, London, United Kingdom

${ }^{\mathrm{e}}$ Institute of Psychiatry, King's College London, United Kingdom

*corresponding author

Inserm U888, Pathologies of the Nervous System, La Colombière Hospital, 39 avenue

Charles Flahault, BP 34493, 34093 Montpellier Cedex 5, France

Tel: (0033)499614570

Fax: (0033)499614579

Email: Joanna.norton@inserm.fr

Key words: general practice, mental illness, doctor-shopping, health service organisation 


\section{Abstract}

Background: doctor-shopping may reflect unmet patients needs and place a significant burden on health resources; however little is known about its underlying reasons and how it relates to mental illness and its recognition in an open access fee-for-service setting.

Methods: in 2003-2004, consecutive patients of 46 French general practitioners (GPs), completed in the waiting room the self-report Patient Health Questionnaire and reported on service use in the past six months. During the consultation, GPs rated the severity of any physical and psychiatric disorder.

Results: of 1079 patients, those rated by the GP as having a common mental disorder were significantly more likely to be doctor-shoppers but only if visiting another GP because of dissatisfaction with previous care $(\mathrm{OR}=2.3,95 \% \mathrm{CI}$ : 1.4-3.7). A similar trend is observed for those identified as having a common mental disorder by the Patient Health Questionnaire. Among patients with a common mental disorder, 'dissatisfied' doctor-shoppers were significantly more likely to be recognised as cases by the GP, adjusting for covariates $(\mathrm{OR}=6$, 95\% CI: 2.1-17.2). This was not the case for those doctor-shopping for practical reasons alone.

Conclusion: doctor-shopping behaviour is associated with higher rates of mental illness and, among cases, an increased likelihood of recognition by the GP, only however for doctorshoppers dissatisfied with previous care. This suggests a benefit to letting patients choose their GP as is the case in France and change if not satisfied.

Key words: general practice, mental illness, doctor-shopping, health service organisation 


\section{Introduction}

Up until recently patients in France were able to access easily and rapidly any GP of their choice. GPs had no patient lists and no gate-keeping role, working mainly alone on a fee-forservice basis with patients reimbursed at a later stage by the state (Bourgueil et al., 2009). Despite high patient satisfaction with the health care system (Degos et al., 2008), this flexibility can lead to a lack of care coordination and continuity, wasted time and expense for the State (Von Korff et al., 1992)(Von Korff et al., 1992). Although changes were introduced in 2004 (Bourgueil et al., 2009; Dourgnon et al., 2007), with lesser reimbursements for doctor-shopping (DS) patients, this service use behaviour is still possible.

DS is usually defined as frequent changes in doctor for the treatment of a same complaint or in a same illness episode (Von Korff et al., 1992). Less is known about DS than other service use behaviours as it can only be studied in settings allowing for it. The reasons for DS are complex. Patient factors which have been suggested include dissatisfaction with or distrust of doctor (Billinghurst \& Whitfield, 1993; Guo et al., 2002; Harris, 2003), a lesser understanding of doctors' explanations and disbelief of diagnosis and treatment (Sato et al., 1995), educational background (Sato et al., 1995), gender (Thomas et al., 1995) and health status (Harris, 2003). DS patients have been found to be more chronically ill and have higher GHQ scores (Sato et al., 1995). Factors related to the health care system include convenience, waiting time, fees and doctor's reputation (Billinghurst \& Whitfield, 1993; Bronstein et al., 2000; Leung et al., 2006; Lo et al., 1994; Yeung et al., 2004). Studies on DS in France have only focused on the prescription of drugs, namely High Dosage Buprenorphine (Feroni et al., 2005; Pradel et al., 2009), DS acting as a mechanism for obtaining multiple prescriptions and accounting for $15 \%$ to $20 \%$ of all prescriptions (Pradel et al., 2009).

The objective of this study is to explore the associations between DS, common mental disorders (CMD) and their recognition. Of particular interest is to discover whether DS 
patients have similar rates of CMDs when considering the reasons for DS and whether this influences GP case-recognition.

\section{Methods}

The study methods have been described elsewhere (Norton et al., 2007). Briefly, the study (2003-2004) was carried out in and around the city of Montpellier, in a sample of GPs practicing in an urban area (with 249 registered GPs for a population of 140.000) and a semirural area (with 73 registered GPs for a population of 80.000). For each GP, a research assistant invited all eligible consecutive patients entering the waiting room to complete questionnaires until 25 patients per GP had participated. Exclusion criteria were: age $(<18$ years), not living in the study area and not consulting for one's self.

\section{Instruments}

During the consultation, GPs completed a short questionnaire with an estimation of severity of physical and psychiatric symptoms on a 5-point scale with a clear indication that ratings of three and above were considered as cases.

Patients completed self-administered questionnaires of which: the anxiety, depression and somatoform disorder modules of the DSM-IV criteria based Patient Health Questionnaire (PHQ) (Spitzer et al., 1999), the Brief Disability Questionnaire (BDQ) (Ustun \& Sartorius, 1995), and adapted versions of the Client Service Receipt Inventory (CSRI) (Beecham \& Knapp, 1992) and the Short Explanatory Model Interview (SEMI) (Lloyd et al., 1998).

\section{Analysis}

The analysis was carried out on the 1079 patients with full datasets for the variables selected for the study, which represents $94 \%$ of the total sample. 
Percentages are presented for categorical variables, medians and ranges for skewed continuous variables. Given the two-stage sampling process, marginal generalised estimating equation (GEE) models were used to test associations. Univariate and multivariate analyses were performed to test the associations between explanatory variables and DS as the dependent variable. Variables with p-values $<0.10$ in the univariate analysis were entered in the multivariate models. Odds ratios (OR) with $95 \%$ confidence intervals (CIs) are given. A second set of analyses was carried out on the subset of PHQ CMD cases with GP caserecognition as the dependent variable. Statistical analyses were performed using SAS version 9.1 (SAS Institute, Cary, NC, USA).

\section{Results}

\section{Description of the GP sample}

The acceptance rate was $32.8 \%$. Participating GPs were significantly younger and acceptance significantly higher in the rural area. In all, 46 GPs participated, 31 in the urban area and 15 in the semi-rural area.

Of the sample, 56\% were male. Median age was 45 (range: $32-59$ ) and the same for both sexes; $60 \%$ had been practicing for at least 10 years and $80 \%$ declared having received some form of mental health training in the last 3 years. Two-thirds practiced alone.

\section{Description of the patient sample}

The response rate was $89.8 \%$. Of the 1079 patients, $61.8 \%$ were female. Median age was 42 (range: $18-93$ ), $49.4 \%$ were married and $33.6 \%$ single; $33.5 \%$ had a high (post-school) educational level. Regarding current occupation, $40.1 \%$ were working, $10.8 \%$ unemployed, $14.1 \%$ students and 35\% retired or other (Norton et al., 2007). Overall, 27.1\% of patients reached criteria for a CMD (ie. major depression, other depressive disorders, panic disorder, 
other anxiety disorders or somatoform disorder) on the PHQ. GPs rated $28.4 \%$ as having a CMD (mild, moderate or severe psychiatric symptomatology). Of the 292 PHQ CMD cases, $51 \%$ were classified as having a CMD by the GP (case-recognition).

Of the sample, $27.7 \%$ were FAs ( 6 or more GPs visits over the past six months, including the survey-day visit). Regarding DS, $72 \%$ of the patients had always visited the same GP, $10 \%$ two, $15 \%$ three and 3\% four or more different GPs. The main reason for visiting a different GP was geographical (patient or GP on holiday, newly moved, travelling for work, retired) (65\% of DSs), followed by avoiding long waiting times (15.6\%), looking for a convenient appointment (14.6\%), not satisfied with previous GPs (9.3\%), looking for advice from a GP with a speciality (8.9\%), looking for a GP accredited to sign administrative papers or taking credit card (7.4\%), wanting a GP with good listening skills (7\%) and wanting a second advice (6.6\%). In sum, $72 \%$ always saw the same GP (non-DSs), $18.4 \%$ doctor-shopped for practical reasons only ('practical DSs') and $9.6 \%$ because they were dissatisfied with care previously received ('dissatisfied DSs').

\section{Association between CMDs and DS}

Among dissatisfied DSs, significantly more (44.7\%) met CMD criteria, compared to practical DSs (30.7\%) and non-DSs (23.9\%) (Table 1). GP ratings of psychiatric disorder are significantly lower for practical DSs (22.1\%), than for dissatisfied DSs (51.5\%) or non-DSs (26.9\%) Patients always seeing the same GP and practical DSs have similar rates of FA ( $27.1 \%$ and $25.1 \%$, respectively), compared to significantly higher rates among dissatisfied DSs $(36.9 \%)$.

-insert Table 1 here- 
In the multivariate analysis, patients rated as cases by the GP were significantly more likely to be dissatisfied DSs (Table 2). Patients with a CMD according to the PHQ were significantly more likely to be dissatisfied DSs when adjusting for covariates in Model 1, but not when adjusting for psychological reason for visit and FA behaviour (Model 2). There were not interactions between CMDs and FA behaviour on DS.

-insert Table 2 here-

\section{The effect of DS on GP case-recognition}

Whatever the level of adjustment, dissatisfied DSs were significantly more likely to be recognised by the GP (Table 3).

-insert Table 3 here-

\section{Discussion}

\section{Limits}

The study limitations are described in detail elsewhere (Norton et al., 2007). The main limitation is the low but common GP participation rate (33\%), selecting GPs particularly interested in mental health issues with a high level of training in this area. This, along with the study effect, will no doubt have led to an overestimation of case-recognition (Freeman et al., 2002). DS is recorded over the past six months which is likely to be affected by patient recall bias. Also mental illness influencing DS requires that the patient had the condition at the beginning of the 6-month period which we are not able to establish. Furthermore, DS behaviour is usually defined in terms of multiple visits for a same health condition (Von Korff et al., 1992), however reason for visit was only recorded for the survey-day visit. Despite these limits, the study included a large sample of GP attenders, with a high participation rate, assessed by internationally accepted measures. 


\section{Association between $C M D$ and $D S$}

As found elsewhere, DS patients tend to be younger, more often single, with a higher level of education (Sato et al., 1995). The percentage of unemployed is considerably higher among dissatisfied DSs. With regard to disability, personal and social problems, mental illness as rated by the GP or using the PHQ, practical DSs and non-DSs have similar and lower rates than dissatisfied DSs. On the survey-day, dissatisfied DSs were more likely to be visiting for a psychological reason, according to the patient or the GP, and were more likely to be presenting with psychological symptoms.

In the multivariate analysis, patients rated as CMD cases by the GP were more likely to be dissatisfied DSs but not practical DSs. Although weakened by adjusting for covariates, a similar trend is shown for patients reaching CMD caseness criteria on the PHQ, for both types of DSs. It is difficult to compare these results with other studies as those that examine factors associated with DS do not take into account the reasons for this behaviour (Billinghurst \& Whitfield, 1993; Guo et al., 2002; Harris, 2003; Sato et al., 1995; Thomas et al., 1995). Sato et al. for example found higher GHQ scores among undifferentiated DS patients (Sato et al., 1995).

GP ratings of CMD may be higher among dissatisfied DS because the latter present more often with psychological symptoms. In our study, the percentage of patients visiting the GP for a psychological reason on the survey-day was over twice as high among dissatisfied DSs than others. Even when adjusting for psychological reason for survey-day visit, patients rated as having a CMD by the GP were more likely to be dissatisfied DSs.

The effect of DS on GP case-recognition 
Among CMD cases, dissatisfied DSs were more likely than non-DSs to have their disorder recognised by the GP. Despite large confidence intervals, this relationship remained significant after adjustment for covariates. The higher recognition rate among dissatisfied DSs could be seen as not fitting with the large body of evidence showing that GPs are better able to recognise psychiatric disorders in patients they know well (Bushnell, 2004; Marks et al., 1979; Rosenberg et al., 2002). However, firstly more than half of DSs declared they were visiting their usual GP on the survey-day. Secondly, dissatisfied DSs, regardless of the presence of a CMD, were more likely than others to be consulting for psychological reasons and presenting psychological symptoms, which have been shown to increase recognition (Aragones et al., 2005; Maginn et al., 2004; Tylee \& Gandhi, 2005).

In conclusion, these findings from a large sample of French GP attenders suggest that it is important to consider the reasons for DS, the prevalence of CMDs being particularly high in dissatisfied DSs. Although we cannot firmly conclude that patients with CMDs are more likely than others to DS, we have shown that among CMD patients, dissatisfied DSs are more likely to have their symptoms recognised by the GP. This may be because they select the GP for this ability or because they have learnt to better present their needs, thereby alerting the GP to possible underlying psychiatric symptoms. If this leads to recognition and treatment, what can be regarded as undesirable patient behaviour in terms of continuity of care would turn out to be an effective means of obtaining care. This suggests it can be beneficial to let patients choose their GP as is the case in France and change if not satisfied.

\section{References}

E. Aragones, A. Labad, J. L. Pinol, C. Lucena and Y. Alonso (2005). "Somatized depression in primary care attenders." J Psychosom Res 58(2): 145-51.

J. Beecham and M. Knapp. Costing psychiatric interventions. In: G. Thornicroft, C. Brewin and J. Wing, editors. Measuring Mental Health Needs. ed. London: Gaskell; 1992. p. 163-83. 
B. Billinghurst and M. Whitfield (1993). "Why do patients change their general practitioner? A postal questionnaire study of patients in Avon." Br J Gen Pract 43(373): 336-8.

Y. Bourgueil, A. Marek and J. Mousques (2009). "Trois modèles types d'organisation des soins primaires en Europe, au Canada, en Australie et en Nouvelle-Zélande." Quest Eco Santé 141.

B. Bronstein, D. Marcus and W. Cassidy (2000). "Choosing a doctor: an exploratory study of factors influencing patients' choice of a primary care doctor." Journal of Evaluation in clinical Practice 6: 255-262.

J. Bushnell (2004). "Frequency of consultations and general practitioner recognition of psychological symptoms." Br J Gen Pract 54(508): 838-43.

L. Degos, F. Romaneix, P. Michel and J. Bacou (2008). "Can France keep its patients happy?" Bmj 336(7638): 254-7.

P. Dourgnon, S. Guillaume, M. Naiditch and C. Ordonneau (2007). "Les assurés et le médecin traitant: premier bilan après la réforme." Quest Eco Santé 124.

I. Feroni, P. Peretti-Watel, A. Paraponaris, A. Masut, E. Ronfle, J. C. Mabriez, et al. (2005).

"French general practitioners' attitudes and prescription patterns toward buprenorphine maintenance treatment: does doctor shopping reflect buprenorphine misuse?" J Addict Dis 24(3): 7-22.

G. K. Freeman, J. P. Horder, J. G. Howie, A. P. Hungin, A. P. Hill, N. C. Shah, et al. (2002).

"Evolving general practice consultation in Britain: issues of length and context." Bmj 324(7342): 880-2.

Y. Guo, T. Kuroki, S. Yamamoto and S. Koizumi (2002). "Illness behavior and patient satisfaction as correlates of self-referral in Japan." Family Practice 19: 326-332.

K. M. Harris (2003). "How do patients choose physicians? Evidence from a national survey of enrollees in employment-related health plans." Health Serv Res 38(2): 711-32.

G. M. Leung, R. Y. Yeung, I. O. Wong, S. Castan-Cameo and J. M. Johnston (2006). "Time costs of waiting, doctor-shopping and private-public sector imbalance: microdata evidence from Hong Kong." Health Policy 76(1): 1-12.

K. R. Lloyd, K. S. Jacob, V. Patel, L. St Louis, D. Bhugra and A. H. Mann (1998). "The development of the Short Explanatory Model Interview (SEMI) and its use among primarycare attenders with common mental disorders." Psychol Med 28(5): 1231-7.

A. Y. Lo, A. J. Hedley, G. K. Pei, S. G. Ong, L. M. Ho, R. Fielding, et al. (1994). "Doctorshopping in Hong Kong: implications for quality of care." Int J Qual Health Care 6(4): 37181.

S. Maginn, A. P. Boardman, T. K. Craig, M. Haddad, G. Heath and J. Stott (2004). "The detection of psychological problems by General Practitioners--influence of ethnicity and other demographic variables." Soc Psychiatry Psychiatr Epidemiol 39(6): 464-71.

J. N. Marks, D. P. Goldberg and V. F. Hillier (1979). "Determinants of the ability of general practitioners to detect psychiatric illness." Psychol Med 9(2): 337-53.

J. Norton, G. De Roquefeuil, J. P. Boulenger, K. Ritchie, A. Mann and A. Tylee (2007). "Use of the PRIME-MD Patient Health Questionnaire for estimating the prevalence of psychiatric disorders in French primary care: comparison with family practitioner estimates and relationship to psychotropic medication use." Gen Hosp Psychiatry 29(4): 285-93.

V. Pradel, E. Frauger, X. Thirion, E. Ronfle, V. Lapierre, A. Masut, et al. (2009). "Impact of a prescription monitoring program on doctor-shopping for high dosage buprenorphine."

Pharmacoepidemiol Drug Saf 18(1): 36-43.

E. Rosenberg, M. T. Lussier, C. Beaudoin, L. J. Kirmayer and G. G. Dufort (2002).

"Determinants of the diagnosis of psychological problems by primary care physicians in patients with normal GHQ-28 scores." Gen Hosp Psychiatry 24(5): 322-7. 
T. Sato, M. Takeichi, M. Shirahama, T. Fukui and J. K. Gude (1995). "Doctor-shopping patients and users of alternative medicine among Japanese primary care patients." Gen Hosp Psychiatry 17(2): 115-25.

R. L. Spitzer, K. Kroenke and J. B. Williams (1999). "Validation and utility of a self-report version of PRIME-MD: the PHQ primary care study. Primary Care Evaluation of Mental Disorders. Patient Health Questionnaire." Jama 282(18): 1737-44.

K. Thomas, J. Nicholl and P. Coleman (1995). "Assessing the outcome of making it easier for patients to change general practitioner: practice characteristics associated with patient movements." Br J Gen Pract 45(400): 581-6.

A. Tylee and P. Gandhi (2005). "The importance of somatic symptoms in depression in primary care." Prim Care Companion J Clin Psychiatry 7(4): 167-76.

T. B. Ustun and N. Sartorius, editors. Mental Illness in General Health Care. An International Study. ed. Chichester: John Wiley \& Sons; 1995.

M. Von Korff, J. Ormel, W. Katon and E. H. Lin (1992). "Disability and depression among high utilizers of health care. A longitudinal analysis." Arch Gen Psychiatry 49(2): 91-100. R. Y. Yeung, G. M. Leung, S. M. McGhee and J. M. Johnston (2004). "Waiting time and doctor shopping in a mixed medical economy." Health Econ 13(11): 1137-44. 
Table 1. Sociodemographic and clinical characteristics of the sample according to DS behaviour $(\mathrm{N}=1079)$

\begin{tabular}{|c|c|c|c|c|}
\hline & \multicolumn{4}{|c|}{ Doctor-shopping } \\
\hline & $\begin{array}{l}\text { No (1) } \\
(\mathrm{n}=777)\end{array}$ & $\begin{array}{l}\text { Yes, practical (2) } \\
\quad(\mathrm{n}=199)\end{array}$ & $\begin{array}{l}\text { Yes, dissatisf. prev. care (3) } \\
\qquad(\mathrm{n}=103)\end{array}$ & $\begin{array}{c}\text { p-values } \\
(2 \text { v. } 1)(3 \text { v. } 1)\end{array}$ \\
\hline Study zone (urban) & 64.2 & 72.9 & 78.6 & $0.11,0.06$ \\
\hline Gender, female (\%) & 60.0 & 65.8 & 68.9 & $0.06,0.09$ \\
\hline Age (median, IQR) for $10 \mathrm{yr}$ increase & $46(33)$ & $30(26)$ & $33.5(21.5)$ & $<.0001,<.0001$ \\
\hline \multicolumn{5}{|l|}{ Marital Status (\%) } \\
\hline Married & 52.6 & 42.7 & 38.8 & \\
\hline Single & 28.6 & 48.2 & 41.8 & \\
\hline Div/Sep/Widowed & 18.8 & 9.1 & 19.4 & $<.0001,0.03$ \\
\hline \multicolumn{5}{|l|}{ Educational level (\%) } \\
\hline Low & 30.9 & 17.6 & 26.2 & \\
\hline Medium & 39.1 & 39.7 & 32.0 & \\
\hline High & 30.0 & 42.7 & 41.8 & $0.001,0.21$ \\
\hline \multicolumn{5}{|l|}{ Occupation (\%) } \\
\hline Employed & 40.9 & 38.2 & 37.9 & \\
\hline Unemployed & 9.0 & 11.0 & 23.3 & \\
\hline Student & 8.8 & 32.7 & 18.4 & \\
\hline Retired, other & 41.3 & 18.1 & 20.4 & $<.0001,<.0001$ \\
\hline \multicolumn{5}{|l|}{ Bothered by personal/social probs. (\%) } \\
\hline Not at all & 59.4 & 47.7 & 34.0 & \\
\hline A little & 31.3 & 42.2 & 46.6 & \\
\hline Alot & 9.3 & 10.1 & 19.4 & $0.06,0.0003$ \\
\hline \multicolumn{5}{|l|}{ Disability (\%) } \\
\hline None/mild & 63.1 & 72.9 & 55.3 & \\
\hline Moderate & 25.9 & 23.1 & 26.2 & \\
\hline Severe & 11.0 & 4.0 & 18.5 & $0.01,0.18$ \\
\hline Physical disorder (GP rating) (\%) & 61.4 & 61.8 & 63.1 & $0.99,0.85$ \\
\hline Psychiatric disorder (GP rating) (\%) & 26.9 & 22.1 & 51.5 & $0.19,<.0001$ \\
\hline Common mental disorder (PHQ quest.) (\%) & 23.9 & 30.7 & 44.7 & $0.07,<.0001$ \\
\hline FA: No. of GP visits $\geq 6(\%)$ & 27.2 & 25.1 & 36.9 & $0.74,0.02$ \\
\hline \multicolumn{5}{|l|}{ On the survey-day: } \\
\hline Survey-day GP is usual GP (patient) (\%) & 89.8 & 54.6 & 54.4 & $<.0001,<.0001$ \\
\hline Reason for visit (patient): psychological (\%) & 6.1 & 7.0 & 17.5 & $0.66,0.0002$ \\
\hline Reason for visit (GP): psychological (\%) & 5.8 & 7.1 & 16.5 & $0.39,0.0008$ \\
\hline Presenting symptoms (GP) & 23.3 & 20.1 & 47.6 & $0.38,<.0001$ \\
\hline
\end{tabular}


Table 2. GP service use variables according to GP or questionnaire rated psychiatric disorder: adjusted models $(\mathrm{N}=1079)$

\begin{tabular}{|c|c|c|c|c|}
\hline & & & \multicolumn{2}{|c|}{ doctor-shopping } \\
\hline & & & $\begin{array}{c}\text { Yes, practical reason } \\
\quad(\text { ref }=\text { no })\end{array}$ & $\begin{array}{l}\text { Yes, dissatisf. prev. care } \\
\text { (ref=no) }\end{array}$ \\
\hline & & & OR (95\% CI, p-value) & OR (95\% CI, p-value) \\
\hline \multirow{3}{*}{$\begin{array}{l}\text { Psychiatric disorder } \\
\text { (GP rating) }\end{array}$} & No & & 1 & 1 \\
\hline & Yes & Model 1 & $1.0(0.7-1.5) 0.82$ & $2.6(1.7-4.0)<.0001$ \\
\hline & Yes & Model 2 & $0.99(0.7-1.5) 0.95$ & $2.3(1.4-3.7) 0.0005$ \\
\hline \multirow{3}{*}{$\begin{array}{l}\text { Common mental disorder } \\
\text { (PHQ quest.) }\end{array}$} & No & & 1 & 1 \\
\hline & Yes & Model 1 & $1.5(1.0-2.2) 0.06$ & $1.8(1.1-3.0) 0.032$ \\
\hline & Yes & Model 2 & $1.4(0.9-2.1) 0.08$ & $1.6(1.0-2.6) 0.07$ \\
\hline
\end{tabular}

Model 1: adjusted for socio-demographic variables (age (for 10 year increase), sex, marital status, education, occupation), personal and social problems, disability (2 levels)

Model 2: further adjusted for psychological reason for visit and FA 
Table 3. GP case-recognition according to GP service use: multivariate model ( $\mathrm{N}=292)$

\begin{tabular}{lccc}
\hline & \multicolumn{2}{c}{ GP case-recognition } \\
\hline & $\begin{array}{c}\text { \% of cases } \\
\text { recognised by GP }\end{array}$ & Model 1 & Model 2 \\
\hline Doctor-shopping & 51.1 & 1 & 1 \\
No & 31.7 & $0.6(0.3-1.2) 0.15$ & $0.8(0.40-1.74) 0.62$ \\
YES - practical reason & 76.1 & $3.0(1.2-7.1) 0.014$ & $6.0(2.1-17.2) 0.0009$ \\
YES - dissatisf. prev. care & & & \\
\hline
\end{tabular}

Model 1: adjusted for age, sex, occupation, personal and social problems, disability and physical health problem (GP rating), FA Model 2: further adjusted for seeing personal GP on survey-day

Note: it was not possible to adjust for reason for visit: psychological, as this concerned only 2 CMD patients not recognised by the GP 